\title{
DNA Markers from Different Linkage Regions of Watermelon Genome Useful in Differentiating among Closely Related Watermelon Genotypes
}

\author{
Amnon Levi ${ }^{1}$ and Claude E. Thomas \\ USDA, ARS, U.S. Vegetable Laboratory, 2700 Savannah Highway, \\ Charleston, SC 29414
}

Additional index words. Citrullus lanatus, RAPD, ISSR, AFLP, SRAP, DNA markers, germplasm, vegetables, breeding, triploid

\begin{abstract}
A genetic linkage map was previously constructed for watermelon using a wide testcross population [\{Plant Accession Griffin 14113; Citrullus lanatus var. citroides (L.H. Baiely) Mansf. $\times$ the watermelon cultivar New Hampshire Midget; NHM \{(Citrullus lanatus (Thunb.) Matsum. \& Nakai var. lanatus) $\} \times$ United States Plant Introduction (PI) 386015 \{Citrullus colocynthis (L.) Schrad.\}]. One-hundred forty-six markers [randomly amplified polymorphic DNA (RAPD), intersimple sequence repeat (ISSR), amplified fragment length polymorphism (AFLP), and sequence-related amplified polymorphism (SRAP) markers] unique to NHM and representing different linkage groups on the map were tested for polymorphism among 24 watermelon cultivars limited in genetic diversity. Five (9.4\%) of 53 RAPD, six (40.0\%) of 15 ISSR, $30(81.0 \%)$ of 37 AFLP, and $33(80.5 \%)$ of 41 SRAP markers tested produced polymorphism among the 24 cultivars. The polymorphic markers used in this study are scattered throughout the watermelon genome. However, a large number (19 of the 30) of AFLP markers clustered on one linkage group on the map. The SRAP markers proved to be most effective in producing polymorphism and in representing different linkage regions of watermelon genome. The polymorphic markers represent all $\mathbf{1 0}$ large linkage groups and five of the nine small linkage groups (altogether 15 of 19 linkage groups) of the genetic linkage map constructed so far for watermelon. These polymorphic markers can be useful in DNA fingerprinting of cultivars, in testing seed purity of breeding lines, and in identifying triploid (seedless) hybrid watermelons derived from crosses between closely related tetraploid and diploid lines.
\end{abstract}

Production of seedless watermelons in the United States has increased significantly in recent years, and there is a need to continue developing new seedless watermelon cultivars suitable to consumer needs. Seedless watermelons are triploids resulting from a cross between a tetraploid (female) plant and a diploid (male) plant (Kihara, 1951). The tetraploid plants are being produced by treating apical meristems of diploid $(2 n=2 x=22$; Shimotsuma, 1963; Shimotsuma and Matsumoto, 1957) watermelon plants with the alkaloid colchicine, which inhibits spindle formation and centromer detachment during cell division (Kihara, 1951). The triploid watermelon seeds are produced in isolation plots where tetraploid plants are pollinated by diploid plants. The seeds produced in isolation plots are mostly triploids. However,

\footnotetext{
Received for publication 6 July 2006. Accepted for publication 8 Nov. 2006.

We acknowledge the technical assistance of Laura Pence in developing the molecular markers.

The use of trade names in this publication does not imply endorsement by the USDA of the products named or criticism of similar ones not mentioned. ${ }^{1}$ To whom reprint requests should be addressed; e-mail alevi@saa.ars.usda.gov.
}

with some tetraploid lines, up to $30 \%$ of seeds produced might be tetraploids as a result of self-pollination (Loehrlein and Ray, 1999). Tetraploid seeds are thicker than triploid seeds (Shimotsuma and Matsumoto, 1957). Still, DNA markers can be useful in quality assurance tests to confirm sufficient production of triploid seeds in isolation plots.

DNA markers have been used in genetic studies and in breeding programs of different polyploidy crop plants, including sunflowers (Mokrani et al., 2002), coffee (Herrera et al., 2002), and alfalfa (Barcaccia et al., 2000). Low DNA polymorphism exists among American watermelon cultivars, indicating they are derived from common ancestors (Levi et al., 2001a, 2001b). A set of DNA markers representing different linkage regions of the watermelon genome and producing sufficient polymorphism among genotypes is needed in breeding programs aiming to produce elite triploid (seedless) watermelon lines derived from crosses between closely related diploid and tetraploid breeding lines.

An extended genetic linkage map was constructed for watermelon (Levi et al., 2006). Because of low DNA polymorphism among watermelon cultivars (C. lanatus var. lanatus) (Levi et al., 2001b), the map con- structed using a wide cross [a watermelon cultivar (C. lanatus var. lanatus) and a U.S. Plant Introduction (PI) of the wild C. lanatus var. citroides]. The map contains 360 DNA markers distributed on 19 linkage groups (10 large and nine small linkage groups) and covers a genetic distance of $1976 \mathrm{cM}$ with an average distance of $5.8 \mathrm{cM}$ between two markers. The map consists mostly of randomly amplified polymorphic DNA (RAPD), intersimple sequence repeat (ISSR), amplified fragment length polymorphism (AFLP), and sequence-related amplified polymorphism (SRAP) markers (Levi et al., 2006).

In this study, markers from different linkage groups of the watermelon genetic linkage map (Levi et al., 2006) were examined for polymorphism among watermelon cultivars (diploids $2 n=22$ ) sharing a narrow genetic background (Levi et al., 2001b). A set of markers representing most of the linkage groups and producing sufficient polymorphism among cultivars was assembled. The polymorphic markers can be useful in DNA fingerprinting of watermelon elite breeding lines, in differentiating among closely related diploid and tetraploid breeding lines, and in confirming the production of true $\mathrm{F}_{1}$ hybrid triploid (seedless) watermelon lines.

\section{Materials and Methods}

Plant material. Twenty-four American heirloom cultivars (diploids; $2 n=22$ ), with low DNA polymorphism (Levi et al., 2001b), were selected for this study. In addition, $\mathrm{BC}_{5} \mathrm{~S}_{1}$ plants (with a common genetic background) were used for testing the effectiveness of markers for production of polymorphism among closely related genotypes. The $\mathrm{BC}_{5} \mathrm{~S}_{1}$ plants resulted from the following crosses: an $\mathrm{F}_{1}$ hybrid [U.S. PI 386015 (C. colocynthis) $\times$ 'Griffin 14113' (C. lanatus var. citroides)] was backcrossed with the watermelon cultivar 'Allsweet' (C. lanatus var. lanatus). Then, four backcrosses were performed using the following watermelon cultivars successively: 'Sugar Baby', 'Charleston Gray', 'Charleston Gray', and 'Allsweet' (all are C. lanatus var. lanatus) to produce $\mathrm{BC}_{5}$ plants $[(C$. colocynthis $\times$ C. lanatus var. citroides) C. lanatus var. lanatus]. One $\mathrm{BC}_{5}$ plant was self-pollinated to produce $\mathrm{BC}_{5} \mathrm{~S}_{1}$ seeds. Seedlings of the watermelon cultivars and the $\mathrm{BC}_{5} \mathrm{~S}_{1}$ were grown in the greenhouse $\left(26^{\circ} \mathrm{C} / 20^{\circ} \mathrm{C}\right.$ day/ night temperatures). Young leaves were collected from young plants (2-3 weeks old) and stored at $-80{ }^{\circ} \mathrm{C}$ for DNA isolation.

Isolation of DNA. An improved procedure for isolation of DNA from young leaves of watermelon (Levi and Thomas, 1999) was used in this study.

Randomly amplified polymorphic DNA and intersimple sequence repeat procedures. The RAPD and ISSR markers (Table 1) were analyzed as described in previous studies (Levi et al., 2001b, 2004).

Amplified fragment length polymorphism procedure. The AFLP procedure developed 
Table 1. Sequence of randomly amplified polymorphic DNA and intersimple sequence repeat primers used for producing markers polymorphic among cultivars.

\begin{tabular}{ll}
\hline Primer & \multicolumn{1}{c}{ Sequence $\left(5^{\prime}-3^{\prime}\right)$} \\
\hline U595 $^{z}$ & GTCACCGCGC \\
U610 & TTTGCCGCCC \\
U613 & TGCACCCACG \\
AE04 & CCAGCACTTC \\
G18 & GGCTCATGTG \\
U809 & GAGGAGAGAGAGAGAGG \\
U834 & AGAGAGAGAGAGAGAGCTT \\
U835 & AGAGAGAGAGAGAGAGCTC \\
U856 & ACACACACACACACACCTA \\
U847 & CACACACACACACACAAGC \\
\hline
\end{tabular}

"Primers starting with " $U$ " are from the University of British Columbia.

"Primers starting with "AE" or "G" are from "Operon."

${ }^{\mathrm{x}}$ All intersimple sequence repeat markers are from the University of British Colombia and start with U8.

by Vos et al. (1995) was modified using a commercially available kit (Plant Mapping Kit-Regular Plant Genome; Applied Biosystems, Foster City, Calif.). According to the manufacturer's protocol, a high-quality genomic DNA sampled [500-ng; intact and with a $260 / 280$ optical density (OD) ratio of 1.8 ] from each plant was used in the AFLP analysis with EcoRI-MseI restriction enzymes and primer combinations as described by Levi et al. (2004). AFLP markers (Table 2) were analyzed using a CEQ8800 (capillary system) DNA sequencer (Beckman Coulter, Fullerton, Calif.). For visualization of DNA fragments on the CEQ8800, the EcoRI selective primers were labeled with one of three WellRED dye labels (D2, D3, or D4; Proligo, Boulder, Colo.), as described by Levi et al. (2006).

Sequence-related amplified polymorphism analysis. The SRAP markers were tested for polymorphism among the cultivars using the same procedure used for mapping of watermelon genome (Levi et al., 2006). The SRAP markers polymorphic among cultivars (Table 3) were selected for repeated tests.

Selecting and testing linkage markers for polymorphism. The linkage map (Levi et al.,

Table 2. The amplified fragment length polymorphism primer pairs, their designation, and the size of markers that are polymorphic among the watermelon cultivars.

\begin{tabular}{lcl}
\hline Primer pair & Designation & \multicolumn{1}{c}{$\begin{array}{c}\text { Marker size } \\
\text { (base pair) }\end{array}$} \\
\hline EAAC - MCAG & EACAG & $99 \mathrm{c}, 219 \mathrm{c}, 312 \mathrm{c}$, \\
& & $373 \mathrm{c}$ \\
EACC - MCAA & ECCAA & $482 \mathrm{c}$ \\
EACC - MCAC & ECCAC & $112 \mathrm{c}, 224 \mathrm{c}, 257 \mathrm{c}$ \\
EACC - MCTG & ECCTG & $93 \mathrm{c}, 310 \mathrm{c}$ \\
EAGG - MCTT & EGGTT & $188 \mathrm{c}, 263 \mathrm{c}, 382 \mathrm{c}$ \\
EAGG - MCTC & EGGTC & $199 \mathrm{c}, 223 \mathrm{c}$ \\
EAAG - MCTG & EAGTG & $272 \mathrm{c}, 408 \mathrm{c}$ \\
EAAG - MCTC & EAGTC & $492 \mathrm{c}$ \\
EAAG - MCAT & EAGAT & $104 \mathrm{c}, 113 \mathrm{c}, 121 \mathrm{c}$, \\
& & $138 \mathrm{c}, 152 \mathrm{c}, 427 \mathrm{c}$ \\
EAGG - MCAG & EGGAG & $147 \mathrm{c}, 226 \mathrm{c}, 334 \mathrm{c}$ \\
EACC - MCTA & ECCTA & $187 \mathrm{c}$ \\
EAAG - MCAG & EAGAG & $121 \mathrm{c}, 174 \mathrm{c}$ \\
\hline
\end{tabular}

Table 3. The sequence-related amplified polymorphism forward primers labeled with a DNA sequencing dye (FLP) and the reverse unlabeled primers (RUP) used in different combinations to produce the SRAP markers polymorphic among watermelon cultivars (Table 4).

\begin{tabular}{lcc}
\hline FLP & DYE & Primer sequence $\left(5^{\prime}\right.$ - $\left.^{\prime}\right)$ \\
\hline me1 & D4 & TGAGTCCAAACCGGATA \\
me2 & D3 & TGAGTCCAAACCGGAGC \\
me3 & D2 & TGAGTCCAAACCGGAAT \\
me4 & D4 & TGAGTCCAAACCGGACC \\
me5 & D3 & TGAGTCCAAACCGGAAG \\
ab1 & D2 & AGTGATTCAACCGGAGA \\
ab2 & D4 & AGTGATTCAACCGGATA \\
ab3 & D3 & AGTGATTCAACCGGAGC \\
\hline RUP & & Primer sequence $\left(5^{\prime}-3^{\prime}\right)$ \\
\hline ba1 & & GTCGAGCTGCCAATTATA \\
ba2 & & GTCGAGCTGCCAATTAAT \\
ba3 & & GTCGAGCTGCCAATTTGC \\
ba4 & & GTCGAGCTGCCAATTTTT \\
ba5 & & GTCGAGCTGCCAATTAAA \\
ba6 & & GTCGAGCTGCCAATTAAC \\
ba7 & & GTCGAGCTGCCAATAAA \\
ba8 & & GTCGAGCTGCCAATTATT \\
ba9 & & GTCGAGCTGCCAATTATC \\
ba10 & & GTCGAGCTGCCAATTATG \\
ba11 & & GTCGAGCTGCCAATTGA \\
ba12 & & GTCGAGCTGCCAATTTGT \\
em1 & & GACTGCGTACGAATTAAT \\
em2 & & GACTGCGTACGAATTTGC \\
em3 & & GACTGCGTACGAATTGAC \\
em4 & & GACTGCGTACGAATTTGA \\
em5 & & GACTGCGTACGAATTAAC \\
em6 & GACTGCGTACGAATTGCA \\
\hline & &
\end{tabular}

2006) contains markers unique to the parent Griffin 14113 (C. lanatus var. citroides) or to the parent 'New Hampshire Midget' [NHM (C. lanatus var. lanatus)]. Most of the markers on the linkage map that are unique to the cultivar NHM (Table 1) were tested for their presence or absence in 24 cultivars, and the markers producing polymorphism among cultivars (Table 4) were selected for a repeated test.

Marker nomenclature. The RAPD or ISSR markers (Tables 1 and 4) were designated by their serial number and their size. For example, the 700-base pair (bp) marker produced by primer AE-04 (Operon Biotechnology, Alameda, Calif.), which is unique to NHM, was designated as AE04-700c. The AFLP markers (Tables 2 and 4) were designated by the last two nucleotides on the $3^{\prime}$ of the MseI and EcoRI primers, respectively. For example marker ATGT-157 represents the AFLP marker (with a size of $157 \mathrm{bp}$ ) produced by the selective primers $M s e I-A T T$ and EcoRI-AGT. The SRAP markers were designated by combining the forward and reverse primers (Tables 3 and 4 ) with the marker size (bp). For example, the 316-bp fragment produced in the cultivar NHM by the forward primer Me1 and the reverse primer ba2 (Table 3) is designated as 'Me1ba2-316c' (Table 4).

\section{Results and Discussion}

Most of the markers that are unique to the cultivar NHM and mapped on the linkage map constructed for watermelon (Levi et al.,
2006) were tested for polymorphism among the 24 American watermelon cultivars. The markers tested include 53 RAPD, 15 ISSR, 38 AFLP, and 40 SRAP markers. The markers (Table 4) represent all 10 large linkage groups and five of the nine small linkage groups (altogether 15 of the 19 linkage groups) on the genetic map (Levi et al., $2006)$. Five $(9.4 \%)$ of 53 RAPD, six $(40.0 \%)$ of 15 ISSR, $30(81.0 \%)$ of 37 AFLP, and $33(80.5 \%)$ of 41 SRAP markers tested produced polymorphism among the 24 cultivars (Table 4). The markers represent most linkage regions. However, a large number of the AFLP markers (19 of 30 AFLP markers) represent one major linkage region (Table 4). AFLP markers may tend to cluster in certain genomic regions as shown in mapping of tomato (Saliba-Colombani et al., 2000) and melon genomes (Perin et al., 2002). A previous study (Levi et al., 2004) indicated that AFLP and ISSR markers produced higher polymorphisms among watermelon cultivars as compared with RAPDs. In this study, the SRAP markers proved to be as efficient as the AFLPs in producing polymorphism but more effective in representing the different linkage regions of watermelon genome. The SRAP marker may represent gene sequences. Their analysis is based on polymerase chain reaction amplification of open reading frames (ORFs) using forward and reverse primers designed to preferentially amplify exon (rich in $\mathrm{C}$ and $\mathrm{G}$ nucleotides) and intron regions (rich in $\mathrm{A}$ and $\mathrm{T}$ nucleotides), respectively. The forward primer is a 14 nucleotide sequence rich in $\mathrm{C}$ and $\mathrm{G}$ and three selective bases at the $3^{\prime}$ end, whereas the reverse primer is a 15 nucleotide sequence rich in $\mathrm{A}$ and $\mathrm{T}$ and three selective bases at the $3^{\prime}$ end. The variation in exon, intron, or promoter region sequences produces the polymorphism (Li and Quiros, 2001). Because SRAP markers may represent ORFs, purifying the amplified DNA fragments and sequencing them may connect fingerprint differences to isolated genes. This may form one of the future perspectives of this technique and the base for developing more specialized DNA markers ( $\mathrm{Li}$ and Quiros, 2001).

The markers in this study represent most of the linkage groups identified so far on the linkage map constructed for watermelon (Table 4). The polymorphic markers can be useful in DNA fingerprinting of watermelon cultivars and breeding lines. Additionally, they can be useful in quality assurance tests to confirm purity of diploid (pollinator) and tetraploid plants used in production of triploid hybrid seeds in isolation plots. Indeed, four RAPD [G18-850c (group III), U6102100c (group IV), AE04-700c (group V), and U595-725c (group XIV)] and two ISSR markers [U809-450 (group I) and U835$550 \mathrm{c}$ (group XIII)] were tested for polymorphism among 30 seedlings with common genetic backgrounds $\left(\mathrm{BC}_{5} \mathrm{~S}_{1}\right)$ versus 30 seedlings of the watermelon cultivar 'Crimson Sweet'. All four RAPD and two ISSR markers proved effective in producing polymorphism among the $\mathrm{BC}_{5} \mathrm{~S}_{1}$ plants 
Table 4. Mapping markers (intersimple sequence repeat, randomly amplified polymorphic DNA, amplified fragment length polymorphism, and sequence-related amplified polymorphism) representing different linkage groups on the genetic map constructed for watermelon polymorphic among American heirloom cultivars (diploids; $2 n=22$ ): Allsweet (AS), AU-Producer (AP), Black Diamond (BD), Blackstone (BS), Charleston Gray (CY), Coles Early (CE), Congo (CO), Fairfax (FX), Family Fun (FF), Garrisonian (GN), Hawkesbury (HU), Iopride (IP), Ironsides (IS), Jubilee (JB), King \& Queen (KQ), Kleckely’s Sweet (KS), Klondike (KD), Leesburg (LB), Mickylee (MK), Miles (MS), Minilee (MN), Parker (PK), Picnic (PI), and Stone Mountain (SM).

\begin{tabular}{|c|c|c|c|c|c|c|c|c|c|c|c|c|c|c|c|c|c|c|c|c|c|c|c|c|c|}
\hline Linkage groups & $\mathrm{AS}$ & $\mathrm{AP}$ & $\mathrm{BD}$ & $\mathrm{BS}$ & $\mathrm{CY}$ & $\mathrm{CE}$ & $\mathrm{CO}$ & $\mathrm{FX}$ & $\mathrm{FF}$ & $\mathrm{GN}$ & $\mathrm{HU}$ & IP & IS & JB & $\mathrm{KQ}$ & $\mathrm{KS}$ & KD & $\overline{\mathrm{LB}}$ & MK & MS & $\mathrm{MN}$ & $\mathrm{PK}$ & $\overline{\mathrm{PI}}$ & & $\bar{M}$ \\
\hline \multicolumn{26}{|l|}{ Group I } \\
\hline Me1ba1-185c & 0 & 0 & 0 & 1 & 0 & 0 & 0 & 0 & 0 & 0 & 1 & 1 & 1 & 1 & 1 & 1 & 0 & 0 & 0 & 0 & 0 & 0 & 0 & 0 & 7 \\
\hline Me1ba11-184c & 0 & 1 & 1 & 0 & 0 & 0 & 0 & 1 & 0 & 1 & 0 & 1 & 1 & 1 & 1 & 0 & 1 & 1 & 1 & 0 & 0 & 1 & 1 & 0 & 13 \\
\hline Me3ba1-83c & 0 & 1 & 1 & 1 & 0 & 1 & 0 & 0 & 0 & 1 & 1 & 1 & 1 & 0 & 0 & 0 & 0 & 1 & 1 & 1 & 1 & 0 & 0 & 0 & 12 \\
\hline $\mathrm{Ab} 2 \mathrm{em} 4-90 \mathrm{c}$ & 1 & 1 & 1 & 1 & 1 & 1 & 1 & 1 & 0 & 1 & 1 & 1 & 1 & 1 & 1 & 1 & 1 & 1 & 1 & 1 & 1 & 1 & 1 & 0 & 22 \\
\hline Me4ba8-97c & 1 & 1 & 1 & 1 & 1 & 1 & 1 & 0 & 1 & 1 & 1 & 0 & 1 & 1 & 1 & 1 & 1 & 1 & 1 & 1 & 0 & 1 & 1 & 1 & 21 \\
\hline ECCTG-93c & 1 & 1 & 1 & 1 & 1 & 1 & 0 & 1 & 0 & 0 & 1 & 1 & 1 & 1 & 0 & 1 & 1 & 1 & 1 & 1 & 1 & 1 & 1 & 1 & 20 \\
\hline EAGAT-427c & 1 & 1 & 1 & 1 & 1 & 1 & 1 & 1 & 1 & 1 & 0 & 1 & 1 & 0 & 1 & 1 & 1 & 1 & 1 & 0 & 1 & 1 & 1 & 0 & 20 \\
\hline U809-450c & 0 & 0 & 0 & 0 & 0 & 0 & 0 & 0 & 1 & 0 & 0 & 0 & 0 & 0 & 0 & 0 & 1 & 0 & 1 & 0 & 1 & 0 & 1 & 0 & 5 \\
\hline Group II & & & & & & & & & & & & & & & & & & & & & & & & & \\
\hline Me1em3-281c & 1 & 1 & 1 & 1 & 0 & 1 & 0 & 0 & 0 & 1 & 1 & 1 & 1 & 0 & 1 & 1 & 0 & 0 & 1 & 1 & 0 & 0 & 1 & 1 & 15 \\
\hline Me4ba2-291c & 1 & 1 & 1 & 1 & 0 & 0 & 1 & 0 & 0 & 1 & 1 & 1 & 1 & 0 & 1 & 0 & 1 & 1 & 1 & 1 & 0 & 0 & 1 & 0 & 15 \\
\hline Me3ba6-286c & 0 & 1 & 1 & 1 & 0 & 0 & 0 & 0 & 1 & 0 & 1 & 1 & 0 & 0 & 0 & 0 & 0 & 1 & 1 & 0 & 0 & 0 & 0 & 0 & 8 \\
\hline Ab1ba11-242c & 0 & 0 & 1 & 0 & 0 & 1 & 1 & 0 & 0 & 0 & 1 & 1 & 1 & 0 & 0 & 1 & 1 & 0 & 1 & 1 & 1 & 1 & 1 & 0 & 13 \\
\hline Me1ba7-93c & 1 & 0 & 0 & 0 & 0 & 0 & 0 & 0 & 0 & 0 & 1 & 0 & 0 & 0 & 1 & 0 & 0 & 0 & 0 & 0 & 0 & 0 & 1 & 1 & 5 \\
\hline Me3ba1-173c & 0 & 0 & 0 & 0 & 0 & 1 & 0 & 1 & 0 & 0 & 0 & 0 & 1 & 0 & 0 & 0 & 0 & 0 & 1 & 1 & 0 & 0 & 0 & 0 & 5 \\
\hline Group III & & & & & & & & & & & & & & & & & & & & & & & & & \\
\hline Me1ba2-316c & 0 & 1 & 1 & 1 & 0 & 0 & 1 & 0 & 0 & 1 & 1 & 1 & 0 & 0 & 1 & 0 & 0 & 1 & 1 & 1 & 0 & 0 & 1 & 0 & 12 \\
\hline Me3ba6-181c & 0 & 1 & 1 & 1 & 0 & 1 & 0 & 0 & 0 & 0 & 0 & 1 & 0 & 0 & 1 & 0 & 0 & 1 & 1 & 0 & 0 & 0 & 1 & 0 & 9 \\
\hline Me2ba8-133c & 0 & 1 & 1 & 1 & 0 & 1 & 1 & 1 & 0 & 1 & 1 & 1 & 1 & 1 & 1 & 1 & 1 & 1 & 1 & 1 & 1 & 0 & 0 & 0 & 18 \\
\hline ECCTA-187c & 1 & 1 & 1 & 1 & 1 & 1 & 1 & 1 & 1 & 1 & 0 & 1 & 0 & 0 & 0 & 1 & 1 & 1 & 1 & 1 & 1 & 1 & 0 & 1 & 19 \\
\hline EAGAT-121c & 1 & 1 & 1 & 1 & 1 & 0 & 1 & 1 & 1 & 1 & 1 & 1 & 0 & 1 & 1 & 1 & 1 & 0 & 0 & 1 & 1 & 1 & 1 & 0 & 19 \\
\hline U834-575c & 1 & 0 & 1 & 1 & 0 & 0 & 1 & 0 & 1 & 1 & 0 & 0 & 1 & 0 & 0 & 1 & 0 & 0 & 1 & 0 & 1 & 0 & 0 & 0 & 10 \\
\hline G18-850c & 0 & 1 & 0 & 1 & 0 & 1 & 1 & 1 & 1 & 1 & 1 & 1 & 1 & 1 & 1 & 1 & 1 & 1 & 1 & 1 & 1 & 1 & 1 & 1 & 21 \\
\hline Group IV & & & & & & & & & & & & & & & & & & & & & & & & & \\
\hline Me4ba5-163c & 1 & 1 & 1 & 1 & 0 & 1 & 1 & 1 & 0 & 1 & 1 & 1 & 0 & 1 & 1 & 1 & 1 & 1 & 1 & 0 & 1 & 1 & 1 & 0 & 19 \\
\hline ECCAC-112c & 1 & 1 & 1 & 1 & 1 & 1 & 1 & 1 & 1 & 1 & 1 & 1 & 1 & 0 & 0 & 1 & 1 & 0 & 1 & 1 & 1 & 1 & 1 & 1 & 21 \\
\hline U610-2100c & 1 & 1 & 1 & 0 & 1 & 0 & 1 & 1 & 1 & 0 & 1 & 0 & 1 & 1 & 0 & 1 & 1 & 1 & 1 & 1 & 1 & 0 & 1 & 0 & 17 \\
\hline Group V & & & & & & & & & & & & & & & & & & & & & & & & & \\
\hline Me3em1-76c & 1 & 1 & 1 & 1 & 0 & 1 & 0 & 1 & 1 & 0 & 1 & 1 & 0 & 0 & 1 & 1 & 1 & 1 & 1 & 1 & 0 & 1 & 1 & 0 & 17 \\
\hline Me1ba11-76c & 0 & 1 & 1 & 1 & 1 & 1 & 0 & 0 & 0 & 1 & 1 & 1 & 1 & 1 & 1 & 1 & 0 & 1 & 1 & 1 & 1 & 1 & 1 & 0 & 18 \\
\hline Me2ba8-127c & 1 & 1 & 1 & 1 & 0 & 1 & 0 & 1 & 1 & 1 & 1 & 1 & 1 & 1 & 1 & 0 & 0 & 1 & 1 & 1 & 1 & 1 & 1 & 0 & 19 \\
\hline Me2ba8-148c & 0 & 0 & 1 & 1 & 0 & 1 & 0 & 1 & 0 & 0 & 0 & 1 & 1 & 1 & 1 & 0 & 0 & 0 & 1 & 1 & 1 & 0 & 1 & 0 & 12 \\
\hline Me4ba2-173c & 1 & 1 & 1 & 1 & 0 & 1 & 1 & 1 & 0 & 1 & 1 & 1 & 1 & 1 & 1 & 1 & 1 & 1 & 1 & 1 & 0 & 1 & 1 & 1 & 21 \\
\hline Me2em6-147c & 1 & 1 & 1 & 1 & 1 & 1 & 1 & 1 & 0 & 1 & 1 & 1 & 0 & 1 & 1 & 1 & 1 & 1 & 1 & 1 & 1 & 1 & 1 & 1 & 22 \\
\hline AE04-700c & 0 & 0 & 0 & 0 & 0 & 1 & 1 & 0 & 0 & 0 & 0 & 0 & 0 & 0 & 1 & 0 & 0 & 0 & 0 & 0 & 0 & 0 & 0 & 1 & 4 \\
\hline Group VIII & & & & & & & & & & & & & & & & & & & & & & & & & \\
\hline U856-345c & 0 & 1 & 0 & 0 & 1 & 1 & 1 & 1 & 1 & 1 & 0 & 0 & 1 & 1 & 1 & 1 & 1 & 1 & 1 & 0 & 1 & 1 & 1 & 1 & 18 \\
\hline Group X & & & & & & & & & & & & & & & & & & & & & & & & & \\
\hline EAGAG-174c & 0 & 1 & 1 & 1 & 0 & 0 & 1 & 1 & 1 & 1 & 1 & 0 & 0 & 1 & 1 & 0 & 1 & 0 & 0 & 0 & 0 & 0 & 1 & 1 & 13 \\
\hline EAGAG-121c & 1 & 1 & 1 & 1 & 1 & 1 & 1 & 1 & 1 & 1 & 1 & 1 & 1 & 1 & 1 & 1 & 1 & 1 & 1 & 0 & 1 & 1 & 1 & 1 & 23 \\
\hline Group XI & & & & & & & & & & & & & & & & & & & & & & & & & \\
\hline Me1ba8-308c & 0 & 0 & 0 & 0 & 0 & 0 & 0 & 1 & 0 & 0 & 0 & 0 & 1 & 0 & 0 & 0 & 0 & 0 & 0 & 0 & 0 & 0 & 0 & 0 & 2 \\
\hline Me2em5-267c & 1 & 1 & 1 & 1 & 0 & 1 & 1 & 1 & 1 & 1 & 1 & 1 & 0 & 1 & 1 & 1 & 1 & 1 & 1 & 1 & 0 & 1 & 1 & 1 & 21 \\
\hline Group XII & & & & & & & & & & & & & & & & & & & & & & & & & \\
\hline EACAG-219c & 1 & 1 & 1 & 1 & 1 & 0 & 0 & 1 & 0 & 0 & 1 & 1 & 1 & 0 & 1 & 1 & 1 & 1 & 0 & 0 & 0 & 0 & 1 & 0 & 14 \\
\hline ECCAA-482c & 1 & 1 & 0 & 0 & 0 & 0 & 0 & 1 & 0 & 0 & 1 & 0 & 0 & 0 & 0 & 0 & 0 & 0 & 0 & 0 & 0 & 0 & 0 & 0 & 4 \\
\hline EAGAT-152c & 1 & 0 & 0 & 1 & 1 & 0 & 0 & 0 & 0 & 0 & 1 & 1 & 1 & 1 & 0 & 1 & 0 & 0 & 1 & 0 & 1 & 1 & 1 & 0 & 12 \\
\hline EGGTC-223c & 1 & 1 & 1 & 1 & 1 & 1 & 0 & 1 & 0 & 0 & 1 & 1 & 1 & 1 & 1 & 1 & 0 & 1 & 1 & 1 & 1 & 1 & 1 & 1 & 20 \\
\hline EGGTT-382c & 0 & 0 & 0 & 0 & 1 & 0 & 0 & 0 & 0 & 0 & 0 & 1 & 1 & 0 & 0 & 0 & 0 & 1 & 1 & 0 & 1 & 0 & 1 & 0 & 7 \\
\hline EGGTT-263c & 0 & 1 & 1 & 1 & 1 & 0 & 0 & 0 & 0 & 0 & 1 & 1 & 1 & 0 & 1 & 1 & 1 & 1 & 1 & 0 & 1 & 1 & 1 & 1 & 16 \\
\hline EAGTG-408c & 0 & 0 & 0 & 0 & 1 & 1 & 0 & 0 & 0 & 0 & 0 & 1 & 0 & 0 & 1 & 1 & 0 & 1 & 1 & 0 & 1 & 1 & 1 & 1 & 11 \\
\hline EAGAT-138c & 1 & 0 & 0 & 1 & 1 & 0 & 0 & 0 & 0 & 0 & 1 & 1 & 1 & 0 & 0 & 1 & 1 & 1 & 1 & 1 & 1 & 1 & 1 & 0 & 14 \\
\hline EACAG-312c & 0 & 0 & 1 & 1 & 1 & 0 & 0 & 0 & 0 & 0 & 1 & 1 & 1 & 0 & 0 & 1 & 0 & 1 & 0 & 0 & 0 & 0 & 0 & 0 & 8 \\
\hline EACAG-373c & 0 & 0 & 1 & 1 & 1 & 0 & 0 & 0 & 0 & 0 & 0 & 1 & 0 & 0 & 0 & 0 & 0 & 0 & 0 & 0 & 0 & 0 & 0 & 0 & 4 \\
\hline ECCAC-257c & 1 & 0 & 1 & 1 & 1 & 1 & 0 & 0 & 0 & 0 & 0 & 1 & 1 & 0 & 0 & 1 & 1 & 0 & 1 & 0 & 1 & 1 & 1 & 1 & 14 \\
\hline ECCAC-224c & 1 & 0 & 1 & 1 & 1 & 0 & 0 & 0 & 0 & 0 & 0 & 1 & 1 & 0 & 0 & 1 & 0 & 0 & 1 & 0 & 1 & 1 & 1 & 1 & 12 \\
\hline ECCTG-310c & 1 & 0 & 1 & 1 & 1 & 1 & 0 & 0 & 0 & 0 & 1 & 1 & 1 & 0 & 1 & 1 & 0 & 1 & 1 & 0 & 1 & 1 & 1 & 1 & 16 \\
\hline EAGTC-492c & 1 & 0 & 1 & 1 & 1 & 1 & 0 & 0 & 0 & 0 & 1 & 1 & 1 & 1 & 1 & 1 & 0 & 1 & 1 & 1 & 1 & 1 & 1 & 1 & 18 \\
\hline EGGTC-199c & 1 & 0 & 1 & 1 & 1 & 1 & 0 & 0 & 0 & 0 & 1 & 1 & 1 & 1 & 1 & 1 & 0 & 1 & 1 & 1 & 1 & 1 & 1 & 1 & 18 \\
\hline EGGTT-188c & 1 & 0 & 1 & 1 & 1 & 1 & 0 & 0 & 0 & 0 & 1 & 1 & 0 & 0 & 1 & 1 & 0 & 1 & 1 & 0 & 1 & 1 & 1 & 1 & 15 \\
\hline EGGAG-226c & 0 & 0 & 0 & 1 & 1 & 0 & 0 & 0 & 0 & 0 & 0 & 1 & 1 & 0 & 1 & 1 & 1 & 1 & 1 & 0 & 1 & 1 & 1 & 0 & 12 \\
\hline EGGAG-334c & 0 & 0 & 0 & 1 & 1 & 0 & 0 & 0 & 0 & 0 & 0 & 0 & 1 & 1 & 0 & 1 & 0 & 0 & 1 & 0 & 1 & 0 & 1 & 0 & 8 \\
\hline EAGTG-272c & 0 & 0 & 0 & 1 & 1 & 0 & 0 & 0 & 0 & 0 & 1 & 1 & 1 & 0 & 1 & 1 & 1 & 1 & 1 & 0 & 1 & 1 & 1 & 1 & 14 \\
\hline Group XIII & & & & & & & & & & & & & & & & & & & & & & & & & \\
\hline Me2ba5-226c & 0 & 0 & 1 & 1 & 0 & 0 & 0 & 1 & 0 & 0 & 1 & 0 & 0 & 0 & 0 & 1 & 0 & 0 & 1 & 0 & 0 & 0 & 0 & 0 & 6 \\
\hline Me3ba1-63c & 0 & 0 & 1 & 0 & 0 & 1 & 0 & 0 & 0 & 0 & 1 & 0 & 1 & 0 & 1 & 1 & 0 & 1 & 0 & 1 & 0 & 0 & 0 & 0 & 8 \\
\hline EAGAT-113c & 1 & 1 & 1 & 1 & 1 & 1 & 1 & 1 & 1 & 1 & 1 & 1 & 1 & 1 & 1 & 1 & 0 & 1 & 1 & 0 & 1 & 1 & 1 & 0 & 21 \\
\hline U835-550c & 1 & 1 & 1 & 1 & 1 & 0 & 1 & 1 & 1 & 1 & 0 & 0 & 0 & 0 & 1 & 0 & 0 & 0 & 0 & 0 & 0 & 0 & 1 & 1 & 12 \\
\hline
\end{tabular}

(Continued on next page) 
Table 4. (continued) Mapping markers (intersimple sequence repeat, randomly amplified polymorphic DNA, amplified fragment length polymorphism, and sequence-related amplified polymorphism) representing different linkage groups on the genetic map constructed for watermelon polymorphic among American heirloom cultivars (diploids; $2 n=22$ ): Allsweet (AS), AU-Producer (AP), Black Diamond (BD), Blackstone (BS), Charleston Gray (CY), Coles Early (CE), Congo (CO), Fairfax (FX), Family Fun (FF), Garrisonian (GN), Hawkesbury (HU), Iopride (IP), Ironsides (IS), Jubilee (JB), King \& Queen (KQ), Kleckely's Sweet (KS), Klondike (KD), Leesburg (LB), Mickylee (MK), Miles (MS), Minilee (MN), Parker (PK), Picnic (PI), and Stone Mountain (SM).

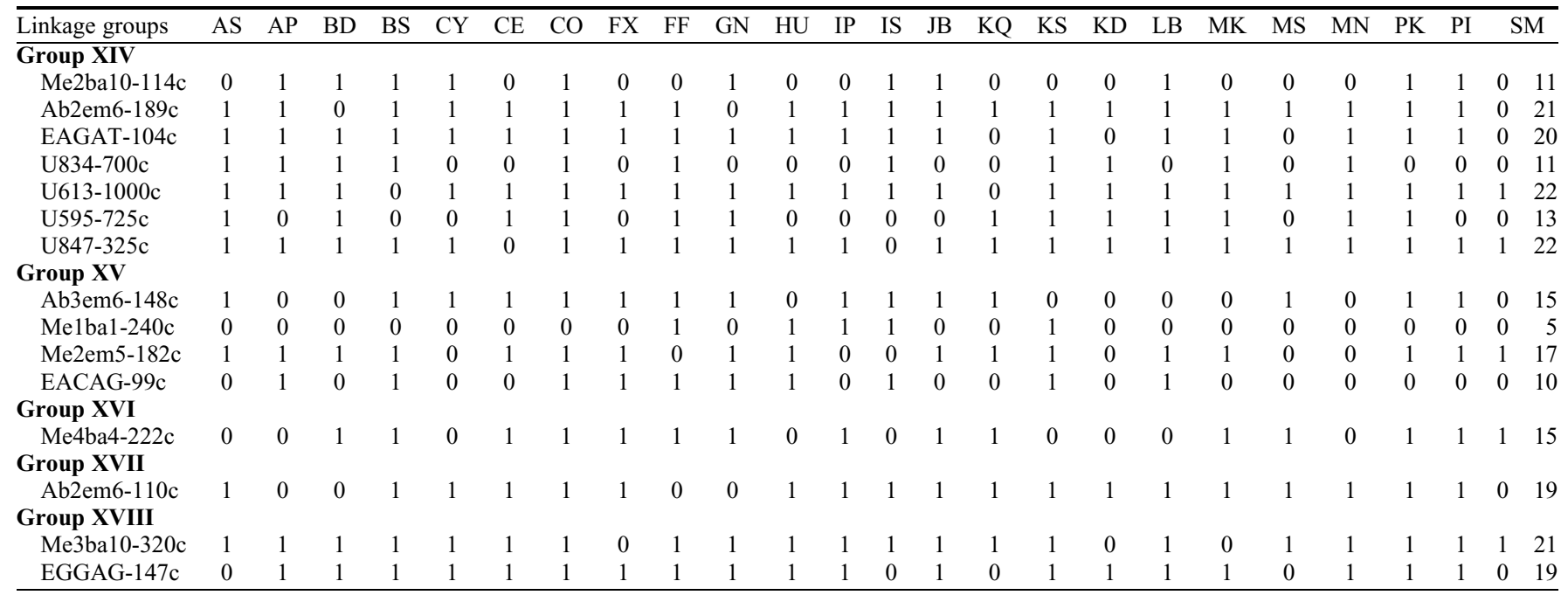

$\begin{array}{llllllllllllllllllllll}1 & 2 & 3 & 4 & 5 & 6 & 7 & 8 & 9 & 10 & 11 & 12 & 13 & 14 & 15 & 16 & 17 & 18 & 19 & 20 & 21 & 22\end{array}$
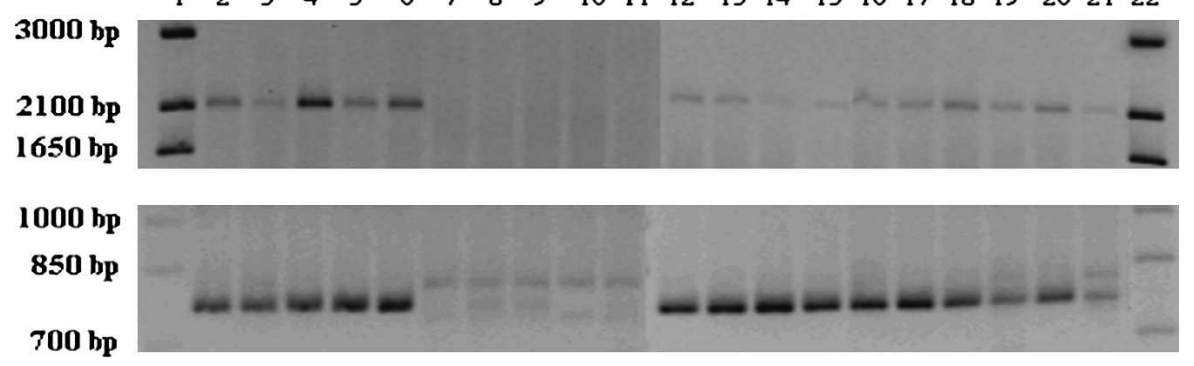

Fig. 1. Randomly amplified polymorphic DNA markers U610-2100c (upper figure) and U595-725c (lower figure) are polymorphic among plants of a breeding material $\left(\mathrm{BC}_{5} \mathrm{~S}_{1}\right.$ generation, lanes 2-11) and monomorphic among plants of the watermelon cultivar 'Crimson Sweet' (lanes 12-21). Size markers on each side (lanes 1 and 22) are of the 1-kb Plus DNA Ladder (Invitrogene, Carlsbad, Calif.).

and were monomorphic among most of the 'Crimson Sweet' plants (Fig. 1). Although the SRAP markers may produce a number of codominant markers (as indicated by $\mathrm{Li}$ and Quiros, 2001), all markers in this study are of dominant nature (present or absent). Codominant markers, including simple sequence repeat (SSR) markers, are considered more effective in breeding programs than dominant markers as shown in melon (Danin-Poleg et al., 2000; Gonzalo et al., 2001). However, it has been a challenging task to develop codominant SSR markers in watermelon as has been indicated in our recent mapping study (Levi et al., 2006). The assembly of markers from different linkage regions of the watermelon genome is vital in differentiating among watermelon genotypes. A saturated linkage map with a large number of polymorphic markers is needed in watermelon breeding programs. The polymorphic markers representing different linkage regions may also be useful in breeding programs enhancing the genetic base of cultivated watermelons through the development of introgression lines and single-segment substitution lines as shown for rice (Oryza sativa L.) (Xi et al., 2006) and tomato (Solanum lycopersicum) (Gur and Zamir, 2004).

\section{Literature Cited}

Barcaccia, G., E. Albertini, D. Rosellini, S. Tavoletti, and F. Veronesi. 2000. Inheritance and mapping of $2 n$-egg production in diploid alfalfa. Genome 43:528-537.

Danin-Poleg, Y., N. Reis, S. Baudracco-Arnas, M. Pitrat, J.E. Staub, M. Oliver, P. Arus, C.M. deVicente, and N. Katzir. 2000. Simple sequence repeats in Cucumis mapping and map merging. Genome 43:963-974.

Gonzalo, M.J., M. Oliver, J. Garcia-Mas, A Monfort, R. Dolcet-Sanjuan, N. Katzir, P. Arus, and A.J. Monforte. 2001. Simple-sequence repeat markers used in merging linkage maps of melon (Cucumis melo L.). Theor. Appl. Genet. 110:802-811.

Gur, A. and D. Zamir. 2004. Unused natural variation can lift yield barriers in plant breeding. PLoS Biol. 2:1610-1615.

Herrera, J.C., M.C. Combes, H. Cortina, G. Alvarado, and P. Lashermes. 2002. Gene introgression into Coffea arabica by way of triploid hybrids
(C. arabica $\times$ C. canephora). Heredity 89 : 488-494.

Kihara, H. 1951. Triploid watermelons. Proc. Amer. Soc. Hort. Sci. 58:217-230.

Levi, A. and C.E. Thomas. 1999. An improved procedure for isolation of high quality DNA from watermelon and melon leaves. Cucurbit Genet. Coop. Rpt. 22:41-42.

Levi, A., C.E. Thomas, A.P. Keinath, and T.C. Wehner. 2001a. Genetic diversity among watermelon (Citrullus lanatus and Citrullus colocynthis) accessions. Genet. Res. Crop Evol. 48:559-566.

Levi, A., C.E. Thomas, T.C. Wehner, and X. Zhang. 2001b. Low genetic diversity indicates the need to broaden the genetic base of cultivated watermelon. HortScience 36: 1096-1101.

Levi, A., C.E. Thomas, M. Newman, O.U.K. Reddy, X. Zhang, and Y. Xu. 2004. ISSR and AFLP markers sufficiently differentiated among American watermelon cultivars with limited genetic diversity. J. Amer. Soc. Hort. Sci. 129:553-558.

Levi, A., C.E. Thomas, T. Trebitsh, A. Salman, J. King, J. Karalius, M. Newman, O.U.K. Reddy, Y. Xu, and X. Zhang. 2006. An extended linkage map for watermelon based on SRAP, AFLP, SSR, ISSR and RAPD markers. J. Amer. Soc. Hort. Sci. 131:393-402.

Li, G. and C.F. Quiros. 2001. Sequence-related amplified polymorphism (SRAP), a new marker system based on a simple PCR reaction: Its application to mapping and gene tagging in Brassica. Theor. Appl. Genet. 103:455-461.

Loehrlein, M. and D. Ray. 1999. Triploid and tetraploid watermelon (Citrullus lanatus [Thunb.] Matsum. and Nakai) seed size and weight. Cucurbit Genet. Coop. Rpt. 22:34-37.

Mokrani, L., L. Gentzbittel, F. Azanza, L. Fitamant, G. Al-Chaarani, and A. Sarrafi. 2002. Mapping and analysis of quantitative trait loci for grain oil content and agronomic traits using AFLP and SSR in sunflower (Helianthus annuus L.). Theor. Appl. Genet. 106:149156.

Perin, C., S. Hagen, V. De Conto, N. Katzir, Y. Danin-Poleg, V. Portnoy, S. Baudracco-Arnas, 
J. Chadoeuf, C. Dogimont, and M. Pitrat. 2002. A reference map of Cucumis melo based on two recombinant inbred line populations. Theor. Appl. Genet. 104:1017-1034.

Saliba-Colombani, V., M. Causse, L. Gervais, and J. Philouze. 2000. Efficiency of RFLP, RAPD, and AFLP markers for the construction of an intraspecific map of the tomato genome. Genome 43:29-40.
Shimotsuma, M. 1963. Cytogenetic and evolutionary studies in the genus Citrullus. Seiken Jiho 15:24-34.

Shimotsuma, M. and K. Matsumoto. 1957. Comparative studies on the morphology of polyploidy watermelon seeds. Seiken Ziho 8:67-74.

Vos, P., R. Hogers, M. Beeker, M. Reijans, T. Vandelee, M. Hornes, A. Frijiters, J. Pot, J. Peleman, M. Kuiper, and M. Zabeau. 1995.
AFLP - a new technique for DNA fingerprinting. Nucleic Acids Res. 23:4407-4414.

Xi, Z.Y., F.H. He, R.Z. Zeng, Z.M. Zhang, X.H.

Ding, W.T. Li, and G.Q. Zhang. 2006. Development of wide population of chromosome single-segment substitution lines in the genetic background of an elite cultivar of rice (Oryza sativa L.). Genome 49:476484. 